\title{
Legal and Statistical Framework of Climate Change from the EU and International Point of View
}

\author{
By Aslı Gül Öncel* \\ Theodore Tzanakis
}

\begin{abstract}
Climate change is not only ecological circumstance but also related with economy, law, energy, industrial processes and daily life habits. Within the framework of our work, we will focus on the factors affecting the climate like greenhouse effect, carbon emissions, methane effect and on different climate change scenarios. A literature review will be given on the first part. A big effort is made on International and European Law basis for facing the Climate Change and the rapid environmental consequences. EU member countries accept urgent need for the protection of the environment which plays a great role in Climate Change. A comprehensive legal approach will be done from the side of EU law and International law on Climate Change and environmental law. An extensive information will be given about different conventions and agreements like UN Climate Convention, Paris Convention, Kyoto Protocol, UNFCCC Meetings, the Aarhus Convention and other international Fora. Special attention will be given to the human Rights related with the Climate Change and to the sanctions provided. The Study will explore the legal framework on the European and International Jurisprudence. Second aim of our work is also to use statistical methods and tools about climate change. Chosen statistical methods with current statistical data will help to evaluate countries. We also focus on making prediction for the future and to show the trend of global warming as long as the current activities continue. On this view, we will examine if the recommendations that we will develop will be taken in consideration how this trend will be affected. The legal recommendations and statistical studies will be an important step to prevent Climate Change.
\end{abstract}

Keywords: Climate Change, Environment, Law, Statistics.

\section{Introduction}

"Man has the fundamental right to freedom, equality and adequate conditions of life, in an environment of a quality that permits a life of dignity and well-being". This principle is declarated in The United Nations Conference on the Human Environment at Stockholm on 1972. The Declaration accept that environmental protection is a pre-condition to the enjoyment of internationally-guaranteed human rights.

An Earth-wide temperature boost and environmental change, that are influencing the entire world, have turned out to be vital issues that all nations should avoid potential risk as well. Environmental change represents a big danger

*Associate Professor, Galatasaray University, Turkey.
${ }^{*}$ Judge, Supreme Civil and Criminal Court of Greece, Greece.

https://doi.org/10.30958/ajs.5-4-1

doi=10.30958/ajs.5-4-1 
to human life and impacts, straightforwardly and in a roundabout way, a variety of globally ensured human rights. In this context, Climate change and global warming are the greatest threats confronting the Earth. The atmosphere contains nitrogen $(78 \%)$, oxygen $(21 \%)$, argon $(0.93 \%)$ vapor and carbon dioxide $(0.036)$ that let in sunlight but take in the heat that is radiated back off the Earth.This natural process, called the Greenhouse effect keeps the Earth's temperature at a level that supports life. Some greenhouse gases such as carbon dioxide arise naturally, exhaled to the atmosphere through natural processes and human activities. Others are generated and exhaled through human activities.

In this study, we first give a general review about the Climate Change. Environment Conventions and agreements will be reviewed on second part. On third part, we will show the relationship between climate change and human rights. As the climate change problems have related with law, we examine some international cases concerning the violation of some human rights. Our work will continue by statistical method focused on $\mathrm{G} 7$ countries' $\mathrm{CO}_{2}$ emissions/year in the aim of looking for the differences between them. The next part of our work will continue by predictions for the future as long as the current industrial activities continue and we will conclude with findings of our research.

\section{Climate Change}

Earth's globally averaged temperature for 2017 made it the third warmest year in National Oceanic and Atmospheric Administration's (NOAA) 138-year climate record, behind warmest 2016 and second warmest 2015 (Schmidt and Arndt, 2018). The average global temperature on Earth has increased by about $0.8^{\circ}$ Celsius since 1880 . Two-thirds of this global warming has existed since 1975 at an estimate of $0.15-0.20^{\circ} \mathrm{C}$ per decade. This happened due to natural reasons or to human activities that conclude in the emission of greenhouse gases. The energy reserves in the ground are very limited while their use grows significantly every year. In addition to this scarcity problem, the burning of fossil fuels releases all manner of pollutants into the air with dangerous effects on human health, and greenhouse gases which threaten the environment (Öncel, 2012). Over the last 150 years, global concentrations of greenhouse gases have increased considerably. These emitted gases have a long lifespan and cause major global warming (Curson, 2018). The essential origin of Greenhouse gases are mainly burning of fossil fuels, deforestation, transportation, electricity production, industry, agriculture and increase in population. Carbondioxyde $\left(\mathrm{CO}_{2}\right)$, Methane $(\mathrm{CH} 4)$, Nitrous Oxide $\left(\mathrm{N}_{2} \mathrm{O}\right)$ and Fluorinated gases are basic greenhouse gases. Carbon dioxide increase in the atmosphere through burning fossil fuels like oil, coal or natural gas, waste and also as a result of certain chemical reactions. For example, manufacture of cement has big share in chemical reactions reason. Carbondioxide is sequestered from the atmosphere via photosynthesis (EPA, 2018). Methane is mostly exhaled during the extraction of coal, natural gas and oil. Some agricultural process and also corrosion of solid waste in disposal area can create methane emissions. Agricultural and some industrial process are some of the reasons of 
nitrous oxide emissions. Fluorinated gases are produced by industrial process. Despite the fact that they do not harm the atmospheric ozone layer however their global warming effect is 23000 times greater than carbon dioxide (European Commission, 2018).

Generally, the average citizen has developped a culture that create or tolerates environmental pollution until some major environmental event occurs. However not all citizens have the same capacity to generate pollution. Many criteria affect on each country's share of $\mathrm{CO}_{2}$ emissions. Data collected by the International Energy Agency (IEA) measure worldwide carbon dioxide emissions for year 2015. This one is composed of oil and other fuels, including industrial waste and non-renewable municipal waste, the coal, the natural gas. In first 3 ranking of 2015 total carbondioxyde emissions (MMT-million metric tons) from fuel combustion, we see in order China (9040.74 MMT), United States (4997.50 MMT) and India (2066.01 MMT). We observe from the rest of data that principal carbon dioxide emmiting countries are the developed and major emerging economy ones. At this point, one of the opinions is that the capitalocene is a concept that takes as a starting point the idea that capitalism is the main cause of current environmental imbalances. This concept alternative to the concept of anthropocene and first time proposed in 2009 by Andreas Malm, a PhD student at Lund university in Sweden. The Capitalocene signifies capitalism as a way of organizing nature (Moore, 2016) and Malm clearly precise that "Blaming all of the humanity for climate change lets capitalism off the hook" (Malm, 2015). From that point of view, we can say that we would no longer speak only of living the era of the anthropocene, but of the capitalocene, as they are more responsible than others in the use of fossil fuels. Environmental footprint per each country appears to be one of the supporting argument of this idea for the reason that not all countries pollute the environment on same level.

Environmental footprint plays a great role in climate change problems and its sustainability depends on the size of humanity's footprint relative to Earth's capacity. An environmental footprint is the consequence that a person, company or activity has on the environment (Cambridge Dictionnary). ${ }^{1}$ Land, energy, water, material and phosphorous, carbon or climate footprint, nitrogen, biodiversity footprints are indicators of human pressure on the environment. Climate change, water pollution are one of the environmental changes results and human health, economy are resultants impacts of human pressure. It can be seen that the carbon footprint should be reduced by $60 \%$ between 2010-2050 to achieve the climate target of a maximum $2^{\circ} \mathrm{C}$ of global warming (UNEP, 2012). In the aim of achieving this target, some studies show that the actual environmental footprint is not sustainable (Hoekstra and Wiedmann, 2014). We know that global carbon emissions from fossil fuels increased by over 16 times between 1900 and 2008 (Boden et al., 2010). One of the reasons of unsustainability is that most of the environmental agreements have domestic rules in order to reduce greenhouse gas emissions within the concerned country. During the process of carrying production from developped to other countries occured carbon exposure. In this purpose, it is necessary to work on different stages of footprint from national to global scale.

\footnotetext{
${ }^{1}$ https://dictionary.cambridge.org/.
} 
Another reason of unsustainability is observed on social equity and consumers side. As an important example, depending United Nations' the latest year data set in 2014, an average global per-person ecological footprint is 2.8 global hectares, while that the average U.S. citizen is 8.4. Considering other members of G7 countries, the average per-person is 8.0 for Canada, 4.7 for France, 5.0 for Germany, 4.3 for Italy, 4.7 for Japon and 4.8 for UK (Footprintnetwork, 2018). Consumption pattern and intensity of natural resource use or waste generation per unit of product consumed determine footprints per capita. The environmental footprint has to reduce toward sustainable levels and footprints per capita have to concentrate more on identical shares (Jackson, 2009). For this purpose, environmental footprint need to be implemented each of the production and the consumption. In order to prevent an unsustainable environmental footprint each participant of supply chain has a big responsability. Among this, the investors, the suppliers, the customers can be cited (Hoekstra, 2013).

The different consequences of an expanding environmental change dramatically affect poor and minimized individuals everywhere throughout the world, strengthening existing vulnerabilities and extending disparities (Postner and Weisbach, 2010). Environmental change and condition are not just natural wonders; they are likewise straightforwardly related with economy, vitality, modern speculations, social life and law. Under the light of late advancements, climate change seriously affects all parts of our lives including physical and common habitat. So the governments should build their endeavors for discovering arrangements in these regions (McInerney-Lankford, 2009).

European Union has one of the important environmental standards. Under Article 191 of the Treaty on the Functioning of the European Union. "Union policy on the environment shall contribute to pursuit of the following objectives: (a) preserving, protecting and improving the quality of the environment, (b)protecting human health, (c) prudent and rational utilisation of natural resources, (d) promoting measures at international level to deal with regional or worldwide environmental problems, and in particular combating climate change". 2

Second principle of The United Nations Conference on the Human Environment is "The natural resources of the earth, including the air, water, land, flora and fauna and especially representative samples of natural ecosystems, must be safeguarded for the benefit of present and future generations through careful planning or management, as appropriate" (UNFCC, 2018). In this context, conventions and agreements are helpful not only to protect the environment but also to take measures to prevent climate change. In the next section, we will focus on them.

Climate Change moves very fast and the Planet is in very high risk. Climate Change is a very serious and urgent issue because of the high risk of damage and irreversible impacts on ecosystems, societies, and economies (Jaimes, 2015b). Sustainable Development can be the world's strategic action against the Climate Change and the Environmental destruction. ${ }^{3}$ A rebalancing restoring the primacy of addressing climate change in the context of sustainable economic growth and

${ }^{2}$ http://ec.europa.eu/environment/eia/pdf/EIA_rulings_web.pdf.

${ }^{3}$ https://sustainabledevelopment.un.org/rio20. 
development is necessary and very important (Bettelheim and d'Origny, 2002). Furthermore it has to be noted that the Role of the Courts is very important for the Protection of the Environment and implementing the Principle of sustainable development (Almpouras, 2018).

\section{Conventions and Agreements on Climate Change}

On international field the main protection is provided by the following Conventions and Agreements:

(a)Stockholm Conference. This U.N. Conference on the Human Environment, held in Stockholm June 5-16 1972 and it was the UN's first major conference on international environmental issues, and marked a turning point in the development of international environmental politics. ${ }^{4}$ The Conference, the largest international meeting ever held, was attended by 113 nations. More than 100 recommendations for international action, which could establish a significant framework for the world's collective attack on environmental problems, were approved. ${ }^{5}$

(b)UN Climate Convention. The UN Framework Convention on Climate Change (UNFCCC), was agreed in 1992, is the principle global Treaty on battling environmental Change. Its goal is to avert risky man-made obstruction with the worldwide atmosphere framework. ${ }^{6}$

(c) Paris Convention. This Agreement adopted by all UNFCCC Parties in December 2015 is the principal ever general, lawfully restricting worldwide climate change assention. ${ }^{7}$

(d)Kyoto Protocol. This is an international agreement linked to the United Nations Framework Convention on Climate Change, which commits its Parties by setting internationally binding emission reduction targets. ${ }^{8}$ The Protocol has been ratified by 192 of the UNFCCC Parties, including the EU and its member countries. Before 2020, It is world's legal binding instrument for cutting greenhouse gas emissions.

(e)UNFCCC Meetings. 1) Conferences of the Parties (COP). The UNFCCC's top decision making is the yearly Conference of the Parties (COP). All Parties to the Convention can participate. Delegates of business, worldwide organisations, interest groups and associations have the role of Observer. 2) Meetings of Parties to the Kyoto Protocol (CMP) Kyoto's top decision-making body is the COP serving as the Meeting of

\footnotetext{
${ }^{4}$ https://sustainabledevelopment.un.org/milestones/humanenvironment.

${ }^{5}$ http://www.un-documents.net/unchedec.htm.

${ }^{6}$ By the adoption of Paris Agreement the Parties Recognized "that climate change represents an urgent and potentially irreversible threat to human societies and the planet and thus requires the widest possible cooperation by all countries, and their participation in an effective and appropriate international response, with a view to accelerating the reduction of global greenhouse gas emissions". See: https://unfccc.int/resource/docs/convkp/conveng.pdf.

${ }^{7}$ https://unfccc.int/resource/docs/2015/cop21/eng/109r01.pdf.

${ }^{8}$ https://unfccc.int/process/the-kyoto-protocol.
} 
the Parties to the Kyoto Protocol (CMP). All Parties to the Protocol are represented and Governments that are not Parties attend as observers. 3) Bodies Subsidiary. They make the preparation of the decisions held by the COP and CMP and the Meetings take place at the annual COP/CMP and the Bonn climate conference each June.

(f) The Aarhus Convention. ${ }^{10}$ This Convention has provisions for: 1) The right of everyone to get ecological data that is held by public authorities ("access to environmental information"). This can include data on the condition of nature, on strategies or measures taken, or on the condition of human wellbeing and security where this can be influenced by the condition of the earth. Candidates are qualified for acquire this data inside one month of the demand and without saying why they require it. Furthermore, open experts are obliged, under the Convention, to effectively scatter natural data in their ownership 2) The right to participate in environmental decision-making. Courses of action are to be made by open specialists to empower people in general influenced and ecological non-administrative associations to remark on, for instance, proposition for ventures influencing the earth, or plans and projects identifying with nature, these remarks to be considered in basic leadership, and data to be given on an official choices and the purposes behind it ("public participation in environmental decision-making") 3) The right of review procedures to challenge public decisions that have been made without respecting the two previously mentioned ("access to justice") ${ }^{11}$.

(g)Other International Fora. These include the:

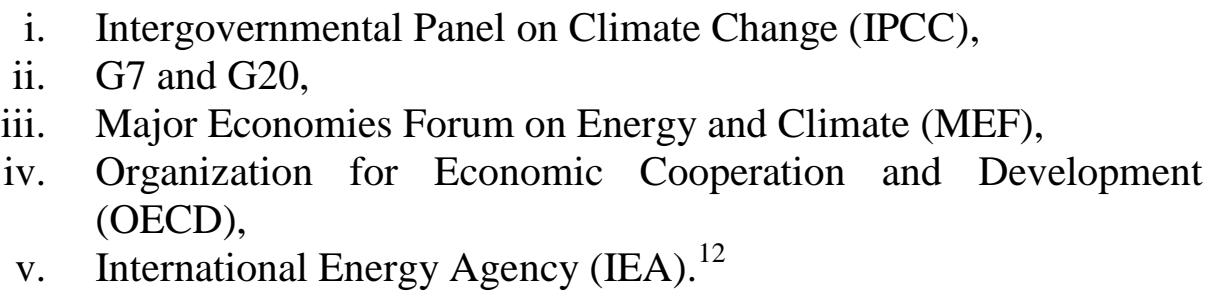

Furthermore, most global Statements on human rights and climate change have underlined the potential antagonistic effects of environmental change on the rights to life, wellbeing, sustenance, water, lodging, improvement and selfassurance. These rights are specified in the main texts of international human rights Law. However not all HRC individuals or UNFCCC parties are signatories of these Conventions.

European Union supports the need for effective protection of the environment the use of which plays an important role in the change of climate. So, the EU law Directive 2008/99/EC on the protection of Environment through criminal law

\footnotetext{
${ }^{9}$ https://ec.europa.eu/clima/policies/international/negotiations_en.

${ }^{10}$ The Aarhus Convention was signed on 25 June 1998 in Aarhus in Denmark and it entered into force on 30 October 2001 (see https://bit.ly/2tkmFO9).

${ }^{11} \mathrm{http}: / /$ ec.europa.eu/environment/aarhus/index.htm.

${ }^{12} \mathrm{https} / / /$ ec.europa.eu/clima/policies/international/negotiations_en.
} 
identifies various ecological offenses that are punishable as a criminal offense (act) in all EU countries. These offenses include environmental crimes and additionally the unlawful task of dangerous activities including the manufacture or treatment of nuclear materials and the unlawful treatment of waste. Under the law, all EU countries need to apply powerful, proportionate and dissuasive criminal sanctions for environmental crimes, if carried out intentionally or with serious negligence. It must be noticed that the Directive provides minimum requirements to be implemented in national criminal laws, i.e: (a) The proposed Directive sets out a list of environmental offenses that considered as criminal offenses by all Member States, if acted by intention or with genuine carelessness. The proposed Directive does not make a list of new unlawful acts. The Member States, by transposing this order will just need to connect to these current prohibitions some criminal assents. (b) Inciting, supporting and abetting the commission of these offenses must be culpable as a criminal offense also. (c) Member States must guarantee that legal persons can be held obligated for offenses conferred for their advantage. This responsibility can be of criminal or other nature (d) Member States must guarantee that the commission of the offenses is liable to successful, proportionate and dissuasive criminal punishments. For legal persons the sanctions can be of a noncriminal nature. (e) The proposed Directive just sets a base standard of ecological protection through criminal law to be adopted by the Member States. The Member States are allowed to keep up or present more stringent defensive measures. (f) The proposed Directive does not set down measures concerning the procedure part of criminal law and it does not touch upon the powers of prosecutors and judges. ${ }^{13}$

\section{Climate Change and Human Rights}

Human Rights most affected by the Climate Change are the following:

1. The right to life. The Universal Declaration of Human Rights stresses "everyone has the right to life, liberty and security of person" and The International Covenant on Civil and Political Rights (ICCPR) provides that "every human being has the inherent right to life." Article 2 of the European Convention on Human Rights (ECHR) proclaims that the right to life shall be protected by law. Thus all States have committed to respect, protect, promote, and fulfill the right to life. So the States should take effective measures against loss of life.

2. The right to self-determination. The right to self-determination is included in the International Covenant on Civil and Political Rights (ICCPR) and in the International Covenant on Economic, Social and Cultural Rights (ICESCR). ${ }^{14}$

\footnotetext{
${ }^{13} \mathrm{http} / / /$ ec.europa.eu/environment/legal/crime/index.htm.

${ }^{14}$ Article 1 of the above International Covenants provides: "All peoples have the right of selfdetermination. By virtue of that right they freely determine their political status and freely pursue their economic, social and cultural development. All peoples may, for their own ends, freely dispose of their natural wealth and resources without prejudice to any obligations arising out of international economic co-operation, based upon the principle of mutual benefit, and international law. In no case may a people be deprived of its own means of subsistence. The States Parties to the
} 
3. The right to development. Under the Provision of article 55 of the UN Charter, States should to promote "conditions of economic and social progress and development". The ICESCR and ICCPR emphasize that all peoples entitled on the Right to Development which presents an integrated framework for the pursuit of all three pillars of the UN Charter - peace and security, human rights and development. Development as "an inalienable human right and all peoples are entitled to participate in, contribute to, and enjoy economic, social, cultural and political development.

4. The right to food. The right to food is included in the Universal Declaration of Human Rights and the International Covenant on Economic Social and Cultural Rights ICESCR. Article 11 of the ICESCR upholds the "fundamental right of everyone to be free from hunger". According to the IPCC, climate change undermines food security; therefore, it threatens the right of food.

5. The right to water and sanitation. General Comment No. 15 of the Committee on Economic, Social and Cultural Rights (CESCR) provides this right expressing: " everybody for adequate, sheltered, satisfactory, physically available and reasonable water for individual and household employments." In determination 64/292, the General Assembly perceived "the right to protected and clean drinking water and sanitation as a human right that is fundamental for the full happiness regarding life and every human right" The right to water and sanitation can be found in law texts, for example, the Convention on the Elimination of Discrimination against Women (CEDAW), among others. States need to receive viable measures to acknowledge, without segregation, the Right to water. The Right to water isn't just a basic condition to survival, but it is also connected with various rights, such as lodging, achievable standard of wellbeing, satisfactory standard of living (Salman, 2004).

6. Right to health. Article 12 of the International Covenant on Economic Social and Cultural Rights (ICESCR) provides the "right to the highest standard of physical and mental health". Climate change creates bigger health disparities between the rich and poor in different parts of the world.

7. The Right to housing. Article 11 of the ICESCR declares that all people are qualified for a satisfactory way of life for themselves and their families including sufficient lodging.

8. The right to education. Under the art 26 of Universal Declaration of Human Rights, "everyone has the right to education." Article 13 of the ICESCR elaborates upon this right, guaranteeing to all persons, free, to compulsory primary education and calling on States to progressively realize free secondary education for all. However, the impacts of climate change and the exigencies which it creates threaten the ability of States to expend maximum available resources for the progressive realization of the right to education and can press children into the labour prematurely.

For the protection of Human Rights related with the Change Climate can be used the following instruments:

present Covenant, including those having responsibility for the administration of Non-SelfGoverning and Trust Territories, shall promote the realization of the right of self-determination, and shall respect that right, in conformity with the provisions of the Charter of the United Nations." 
(a)UN human rights instruments, i.e The International Covenant on Civil and Political Rights (ICCPR) and the International Covenant on Economic Social and Cultural Rights (ICESCR),

(b)Regional human rights instruments, such as the American Convention on Human Rights (AmCHR), the African Convention on Human and Peoples' Rights (AfCHPR) and the European Convention on Human Rights (ECHR). ${ }^{15}$

\section{Cases on Climate Change}

1. The Ogoniland case. It is a case concerning the climate change and the consequent important ecological destructions in Nigeria. SHELL Company has been misusing oil reserves in the Niger Delta since the 1950s. Visit oil slicks have prompted monstrous natural debasement, wrecking both the land and the groundwater. This truly influenced the Ogoni individuals, who live in that location. SHELL, together with the government, were permitted to work by the military administration of Nigeria with no care for health, security or environment protection of the inhabitants living there. Also, the Government basically exercised its military power at the disposal of the oil Corporations, the peaceful Ogoni challenge development was curbed, towns were assaulted, and group pioneers were executed. Furthermore, the military government was in charge of the death and removal of thousands of people. Two NGOs brought a legal action to the African Commission on Human and Peoples' Rights, which found that Nigeria had violated human rights given by the Banjul Charter. Especially, the Right to Health (Article 16), the Right to a good Environment (Article 24), the Right of people groups to dispose the resources, belonging to them (Article 21). The Commission concluded that there was violation of the above Articles of the African Convention expressing that (a) "the Article 24" imposes clear commitments upon a government. The State has to take reasonable measures to fight the biological corruption and promote conservation"; (b) the Right of individuals for disposing their assets (Article 21). The Commission held that the Government has to find ways to keep private parties (i.e., the oil Corporations) from harming the land. The Commission additionally found that the Right to food (provided in Articles 4, 16 and 22 of African Convention, i.e., the rights to life, health, and financial and social development) was violated because the Government did not take measures for the environment protection (Clemens, 2016).

2. Peruvian Saul Lliuva v. German Electricity Producer Company RWE. In November 2015, Saul Lliuya, a Peruvian farmer living in Huaraz, Peru,

\footnotetext{
${ }^{15}$ Although the Europen Convention on Human Rights does not provide for any right to a healthy environment as such, the European Court of Human Rights has developed its case-law in environmental matters. The European Court of Human Rights has held: "neither Article 8 nor any of the other articles of the Convention are specifically designed to provide general protection of the environment as such" (see Kyrtatos v Greece, 2003). The above European Court has held that the following rights have an environmental dimension and importance: (a) Art. 2 (right to life). (b) Art. 8 (right to respect for private and family life) and (c) Art. 1 of the First Protocol to the ECHR (right to property) (see https://bit.ly/2MY7ftA).
} 
documented cases for decisive judgment and damages in a German court against RWE, Germany's biggest power maker. Lliuya's suit affirmed that RWE, having purposely caused Climatic change by producing significant volumes of greenhouse gases (GHGs), having responsibility for the melting of mountain ice glaciers close to his town of Huaraz, populated by 120,000 people. Palcacocha, a frosty lake located above Huaraz, has encountered a significant volumetric increase since 1975, which has quickened since 2003. Lliuya supported that because of the high emission of the gases had compensable expenses to mitigate. Considering that RWE was just the contributor of the outflows in charge of environmental Change and in this way for the lake's development, Lliuya requested that the court arrange RWE to repay him for a part of the costs he and the Huaraz experts had brought for establishing flood protections. The court rejected Lliuya's arguments for declaratory and injunctive relief, and additionally his request for damage and concluded that it couldn't give Lliuya successful review (Lliuya's circumstance would not change, regardless of whether RWE stopped radiating), and that no that no causal link exists between its actions and a supposed flood risk from the glacial lake. ${ }^{16}$ On 30.11.2017, the Appeal Court held that the complaint was too pled and permissible and the case will move forward into the evidentiary phase for deciding (a) whether the Lliuya's house is threatened by flooding or mudslide because of the ongoing increase in the volume of the glacial lake located nearby, and (b) how RWE's greenhouse gas emissions contribute to that risk. The court will review expert opinion on the RWE's Co2 outflows, the contribution of those emissions to Climate Change, the subsequent effect on the Palcaraju Glacier, and RWE's responsibility for causing the above impacts.

3. Greenpeace Nordic v Government of Norway. A legal action against the Norwegian Government brought by Greenpeace Norway, Nature and Youth and the Grandparents Climate Campaign for conceding new oil licenses for drilling the Arctic. The Oslo District Court by his decision held that the Norwegian Government has not violated the Constitution. However the Court held that the right to a healthy environment is protected by the Constitution and the Government must maintain those rights. Reacting to the judgment, Greenpeace Norway said that it's great that the judgment recognizes the Environmental Article in the Norwegian Constitution, however it is disappointing that it is not recognized Norway's responsibility for harming the planet's climate. ${ }^{17}$ On 05.02 .2018 , the above decision was appealed by the Greenpeace Nordic, Nature and Youth.

4. Youth v. the Government of the United States. Another legal action began by a group of American young persons, who are suing the US government for neglecting to check environmental Change. The 21 plaintiffs (between 10 and 21 years of age), come from all from the US, documented Climate Change claim (together with their lawyers and atmosphere researcher) All the children and young people have been affected by Climatic Change. Some of them live on districts being influenced by drought, while others have lost their homes because

\footnotetext{
${ }^{16} \mathrm{http}: / /$ www.justiz.nrw.de/nrwe/lgs/essen/lg_essen/j2016/2_O_285_15_Urteil_20161215.html.

${ }^{17} \mathrm{https}: / / \mathrm{www}$.greenpeace.org/international/press-release/11705/decision-made-in-case-againstar ctic-oil-in-norway-right-to-a-healthy-environment-acknowledged/.
} 
of the floods, or face medical problems because of woods fires. In the their action, entitled "Juliana versus US," the young persons blame the Federal Government for abusing the constitutional rights to life and freedom by neglecting to make a move against Global Warming They support that the Government refuses to secure essential public resources like air and water, which are vital to survival.The trial will begin on 29 October 2018 in Eugene, Oregon. ${ }^{18}$

5. ExxonMobil v. US state lawyers. It is first US legal Action was against for considering the oil Company ExxonMobil which is considered responsible for the Climatic Change The American multinational oil gas enterprise is being sued over neglecting to safeguard Massachusetts people group against pollution relating to Climatic change effects, and misleading the general population about the dangers of Climatic Change. The Action started by a Group of General Attorneys after it became known that Exxon administrators had known about the atmosphere dangers related with petroleum derivatives as early as 1977, but they made a campaign to cover up these findings. ExxonMobil Company denied the claims, and stated that it would battle the claim in court. ${ }^{19}$

6. The Inuit Case. On 2005 Ms. Sheila Watt-Cloutier, elected Chair of the Inuit Circumpolar Conference (ICC), submitted a petition to the Washington DCbased Inter-American Commission on Human Rights seeking relief from violations of the human rights of Inuit resulting from global warming caused by greenhouse gas emissions from the United States of America. The 163-page petition was supported by testimony from 63 named Inuit from northern Canada and Alaska. The petition proves with documents existing, ongoing, and projected destruction of the Arctic environment and the culture and hunting-based economy of Inuit caused by global warming. By the petition before the Inter-American Commission on Human Rights, it was supported that the US, as the biggest emitter of $\mathrm{CO}_{2}$, was responsible for violating human rights provided in the American Declaration of the Rights and Duties of Man (1948). The Inuit supported in their Petition -between the others- the following "The Inuit's fundamental right to enjoy their personal property is violated because climate change has reduced the value of the Inuit's personal effects, decreasing the quality of food and hides, and damaging snowmobiles, dog sleds and other tools. Their right to cultural intellectual property is also violated, because much of the Inuit's traditional knowledge,... has become frequently unreliable or inaccurate as a result of climate change. The Inuit's fundamental rights to health and life are violated as climate change exacerbates pressure on the Inuit to change their diet, which for millennia has consisted of wild meat and a few wild plants. [...] The Inuit's fundamental rights to residence and movement, and inviolability of the home are likewise violated as a result of the impacts of climate change because the physical integrity of Inuit homes is threatened.[...] The Inuit's fundamental right to their own means of subsistence has also been violated as a result of the impacts of climate change. ..." However, the Inter-American Commission on Human

\footnotetext{
${ }^{18}$ http://www.youthvgovthefilm.com.

${ }^{19}$ The US distict Court dismissed Exxon Mobil Corp's lawsuit seeking to stop New York and Massachusetts from probing whether the oil and gas company covered up its knowledge about climate change and lied to investors and the public about it. (see https://bit.ly/2MlVqbK).
} 
Rights decided that it would not consider the petition, arguing that the information that had been provided was insufficient, and so avoided to decide on a politically contentious issue (Clemens, 2016). ${ }^{20}$

7. The Athabaskan Case. On 23.04.2013, the Arctic Athabaskan Council (AAC), represented by Earthjustice and Ecojustice Canada, on behalf of all the Arctic Athabaskan People of Canada and United States, submitted a request before the Inter American Commission of Human Rights. They asked for relief from infringement of the Arctic Athabaskan people groups' human rights. The Athabaskans supported that Canada is universally responsible for dark carbon, which has caused fast Arctic warming and melting. The petition is a detailed and comprehensive document including a analysis of international human rights law and case law, and the evidence of Athabaskan people claiming violations of the human rights. The Commission is asked for making investigation on Change Climate and declaring that Canada's failure to take measures for reducing of black carbon emissions violates rights provided in Article 13 (right to the benefits of their culture), Article 23 (right to property), and Article 11 (right to health)of the American Declaration of the Rights and Duties of Man (1948) (Jaimes, 2015a).

One of the aim of our work is also to use statistical methods and tools about climate change. Via Analysis of variance (ANOVA) which is our chosen statistical method with current statistical data about G7 countries. Those major developed countries share on $\mathrm{CO}_{2}$ emission play a great role in increasing GHG as well as in the increasing global warming. We wanted to show also their attitude to the decisions of Kyoto protocol to take serious measures againts global warming and climate change.

\section{Methodology of Statistical Framework of Climate Change}

First of all, we examined the relationship between climate change and human rights. This relationship is shown on $4^{\text {rd }}$ part of our study. After this stage, we examined European and International 7 legal cases. This part is followed by a statistical analysis. It is supposed that we want to compare the means of $\mathrm{K}$ populations, each of which assumed to have the same variance.Independant random samples of 7 countries' $\mathrm{CO}_{2}$ emissions/year were taken from International Energy Agency (IEA). From these data of G7 countries which are high industrialized ones, we derived the analysis of variance to measure if there is a difference of $\mathrm{CO}_{2}$ emissions after Kyoto protocol. Our test of the equality of population means is based on the assumptions that 7 populations have a common variance. If the null hypothesis that the population means are all the same is true, each of the sums of squares, within-groups variability denoted SSW and betweengroups variability SSG, can be used as the basis for an estimate of the common population of variance. More detailed steps of analysis will be given on the analysis part.

\footnotetext{
${ }^{20} \mathrm{http}: / / \mathrm{www}$.inuitcircumpolar.com/inuit-petition-inter-american-commission-on-human-rightsto-oppose-climate-change-caused-by-the-united-states-of-america.html.
} 


\section{Statistical Analysis}

In this study we use a statistical method, One way analysis of variance (Newbold et al., 2007). Suppose that we have independent random samples of $\mathrm{n}_{1}, \mathrm{n}_{2}, \ldots, \mathrm{n}_{\mathrm{k}}$ observations from $\mathrm{K}$ populations. If the population means are denoted $\mu_{1}, \mu_{2, \ldots} \mu_{K}$, the one-way analysis of variance framework is designed to test the null hypothesis.

$$
\begin{aligned}
& \mathrm{H}_{0}: \mu_{1}=\mu_{2}=\ldots=\mu_{\mathrm{K}} \\
& \mathrm{H}_{1}: \mu_{\mathrm{i}}=\neq \mu_{\mathrm{j}} \text { For at least one pair } \mu_{\mathrm{I}}, \mu_{\mathrm{j}}
\end{aligned}
$$

We will develop a test of the null hypothesis that the K population means are equal, given independent random samples from those populations. The first step is to calculate the sample means for the $\mathrm{K}$ groups of observations. These sample means will be denoted $\overline{x_{1}}, \overline{x_{2}}, \ldots, \overline{x_{K}}$. Formally then,

$$
\bar{x}_{i}=\frac{\sum_{j=1}^{n_{i}} x_{i j}}{n_{i}}(\mathrm{i}=1,2, \ldots, \mathrm{K})
$$

where $n_{i}$ denotes the number of sample observations in group $i$. The null hypothesis of interest specifies that the K populations have a common mean. The next step is to form an estimate of that common mean from the sample observations. This is just the sum of all of the sample values divided by their total number. If we let $n$ denote the total number of sample observations, then,

$$
\mathrm{n}=\sum_{i=1}^{K} n_{i}
$$

The overall mean of the sample observations can be expressed as:

$$
\bar{\chi}=\frac{\sum_{i=1}^{K} \Sigma_{j=1}^{n_{i}} x_{i j}}{n}
$$

where the double summation notation indicates that we sum over all observations within each group and over all groups. That is we sum all of the available observations. An equivalent expression is:

$$
\bar{x}=\frac{\sum_{i=1}^{K} n_{i} \bar{x}_{i}}{n}
$$

The test of equality of population means is based on a comparison of two types of variability exhibited by the sample members. The first is variability about the individual sample means within the $\mathrm{K}$ groups of observations.It is convenient to refer to this as within-groups variability. Second we are interested in the variability among the $\mathrm{K}$ group means. This is called between-groups variability. To measure variability in the first group, we calculate the sum of squares deviations of the observations about their sample mean $\bar{x}_{1}$, that is: 


$$
\begin{aligned}
& \mathrm{SS}_{1=} \sum_{j=1}^{n_{1}}\left(x_{1 j}-\bar{x}_{1}\right)^{2} \\
& \mathrm{SS}_{2}=\sum_{j=1}^{n_{2}}\left(x_{2 j}-\bar{x}_{2}\right)^{2}
\end{aligned}
$$

The total within-groups variability denoted SSW, is then the sum of the sums of squares over all $\mathrm{K}$ groups, that is:

$$
\begin{aligned}
& \mathrm{SSW}=\mathrm{SS}_{1}+\mathrm{SS}_{2}+\ldots+\mathrm{SS}_{\mathrm{K}} \\
& \mathrm{SSW}=\sum_{i=1}^{K} \sum_{j=1}^{n_{i}}\left(x_{i j}-\bar{x}_{i}\right)^{2}
\end{aligned}
$$

The next step is to find a measure of variability between groups. A natural measure is based on the discrepancies between the individual group means and the overall mean. In fact as before these discrepancies are squared giving: $\left(\bar{x}_{1}-\bar{x}\right)^{2},\left(\bar{x}_{2}-\bar{x}\right)^{2}, \ldots,\left(\bar{x}_{K}-\bar{x}\right)^{2}$. In computing the total between-group sum of squares, SSG we weight each squared discrepancy by the number of sample observations in the corresponding group, giving:

$$
\mathrm{SSG}_{=} \sum_{\mathrm{I}=1}^{K} n_{i}\left(\bar{x}_{i}-\bar{x}\right)^{2}
$$

Another sum of squares is often calculated. This is the sum of squared discrepancies of all the sample observations about their overall mean. This is called the total sum of squares and is expressed as:

$$
\mathrm{SST}=\sum_{i=1}^{K} \sum_{j=1}^{n_{i}}\left(x_{i j}-\bar{x}_{i}\right)^{2}
$$

The total sum of squares is the sum of the within-group and between-group sums of squares:

\section{$\mathrm{SST}=\mathrm{SSW}+\mathrm{SSG}$}

After this stage, Within-groups mean square denoted MSW is calculated. On this equation $n-K$ is showing the number of degree of freedom.

$$
M S W=\frac{S S W}{\mathrm{n}-\mathrm{K}}
$$

If the population means are equal, an unbiased estimator of the population variance is obtained by dividing SSG by $(\mathrm{K}-1)$. The resulting quantity is called the between-groups mean square:

$$
M S G=\frac{\text { SSG }}{\mathrm{K}-1}(10)
$$

The test of the null hypothesis is based on the ratio of mean squares:

$$
F=\frac{\text { MSG }}{\text { MSW }}
$$




\section{Findings}

One of the aim of our work is also to use statistical methods and tools about climate change. Via Analysis of variance (ANOVA) which is our chosen statistical method with current statistical data about G7 countries we want first to show their energy and environment polities on global climate change. Those major developed countries share on $\mathrm{CO}_{2}$ emission play a great role in increasing GHG as well as in the increasing global warming. We wanted to show also their attitude to the decisions of Kyoto protocol to take serious measures againts global warming and climate change.

Recognizing that developed countries are principally responsible for the current high levels of Greenhouse gas emissions (GHG) emissions in the atmosphere as a result of more than 150 years of industrial activity, the Kyoto Protocol places a heavier burden on developed nations under the principle of "common but differentiated responsibilities" (UNFCC, 2018). We use G7 countries because of their characteristics of being major industrialized countries. In this purpose, we wanted to examinate if there is a difference of $\mathrm{CO}_{2}$ emission between them after Kyoto protocol entered in force in 16 February 2005. Signature decisions of the countries are that Japon, İtaly, France, U.K.,Germany and Canada are signed. Canada despite its signature in 2005 withdrew Kyoto protocol on 15 December 2012. USA did not sign Kyoto protocol.

Table 1. $\mathrm{CO}_{2}$ Emissions of $\mathrm{G} 7$ Countries after Kyoto Protocol

\begin{tabular}{|l|c|c|c|c|c|c|c|}
\hline & CANADA & JAPON & ITALY & FRANCE & UK & GERMANY & USA \\
\hline $\mathbf{2 0 0 5}$ & 541.2 & 1177.7 & 456.3 & 371.8 & 531.5 & 786.8 & 5702.3 \\
\hline $\mathbf{2 0 0 6}$ & 533.1 & 1162.3 & 449.1 & 362.5 & 532.8 & 799.3 & 5601.7 \\
\hline $\mathbf{2 0 0 7}$ & 564.0 & 1206.4 & 441.3 & 354.4 & 521.6 & 766.8 & 5685.9 \\
\hline $\mathbf{2 0 0 8}$ & 544.0 & 1120.6 & 428.7 & 350.1 & 508.4 & 775.3 & 5511.6 \\
\hline $\mathbf{2 0 0 9}$ & 514.6 & 1059.9 & 383.6 & 333.6 & 459.5 & 720.3 & 5119.9 \\
\hline $\mathbf{2 0 1 0}$ & 528.4 & 1111.8 & 391.9 & 340.8 & 477.0 & 758.9 & 5347.0 \\
\hline $\mathbf{2 0 1 1}$ & 538.8 & 1165.7 & 384.0 & 310.2 & 438.8 & 731.3 & 5211.1 \\
\hline $\mathbf{2 0 1 2}$ & 539.1 & 1208.8 & 366.6 & 313.5 & 462.4 & 744.8 & 5031.3 \\
\hline $\mathbf{2 0 1 3}$ & 552.0 & 1229.6 & 337.5 & 316.2 & 446.0 & 763.9 & 5103.2 \\
\hline $\mathbf{2 0 1 4}$ & 554.4 & 1184.4 & 319.7 & 284.0 & 406.8 & 723.3 & 5168.1 \\
\hline $\mathbf{2 0 1 5}$ & 549.2 & 1141.6 & 330.7 & 290.5 & 389.8 & 729.8 & 4997.5 \\
\hline
\end{tabular}

Source: IEA $\mathrm{CO}_{2}$ Emissions from Fuel Combustion, OECD/IEA, Paris, 2017.

Table 1 shows the $\mathrm{CO}_{2}$ emissions of $\mathrm{G} 7$ countries after Kyoto protocol till 2015. As the most recent data found are on 2015, we could not work on data till 2017 (iea.org). Depending this time serie, we wanted to test if the $\mathrm{CO}_{2}$ emissions of those countries are equal or not.

The null hypothesis to be tested is that the $\mathrm{K}$ population means are equal:

$\mathrm{H}_{0}=\mu_{1}=\mu_{2}=\ldots=\mu_{\mathrm{K}}$ 
And the alternative hypothesis is that:

$\mathrm{H}_{1}: \mu_{\mathrm{i}} \neq \mu_{\mathrm{j}}$ For at least one pair $\mu_{\mathrm{i}}, \mu_{\mathrm{j}}$

We make the following additional assumptions:

1. The population variances are equal.

2. The population distributions are normal.

A test of significance level $\alpha$ is provided by the decision rule.

Reject $\mathrm{H}_{0}$ if $\frac{\mathrm{MSG}}{\mathrm{MSW}}>F_{K-1, n-K, \alpha}$

Where $F_{K-1, n-K_{,} \alpha}$ is the number for which

$\mathrm{P}\left(F_{K-1, n-K}>F_{K-1, n-K, \alpha}\right)=\alpha$

And the random variable $F_{K-1, n-K}$ follows an $\mathrm{F}$ distribution with numerator degrees of freedom $(K-1)$ and denominator degrees of freedom $(n-K)$.The p-value fort his test is the smallest significance value that would allow us to reject the null hypothesis. In this study we use $\alpha=0.05$. Results of one way Anova test are shown in Table 2.

Table 2. One Way ANOVA Test Results

\begin{tabular}{|c|c|c|c|c|c|c|}
\hline ANOVA & & & & & & \\
\hline Source of Variation & $S S$ & $d f$ & $M S$ & $F$ & P-value & F crit \\
\hline Between Groups & 219377142.1 & 7 & 31339591.73 & 3149.729007 & $7.1109 \mathrm{E}-95$ & $\begin{array}{c}2.1263 \\
2428\end{array}$ \\
\hline Within Groups & 795994.6181 & 80 & 9949.932727 & & & \\
\hline & & & & & & \\
\hline Total & 220173136.7 & 87 & & & & \\
\hline
\end{tabular}

The numerator and denominator degrees of freedom are respectively $\mathrm{v} 1=\mathrm{K}$ $1=6$ and $v 2=n-K=67$. Thus, for a $5 \%$ significance level test we have:

$$
F_{\mathrm{v} 1, \mathrm{v} 2, \alpha}=\mathrm{F}_{6,67,0.05}=2.12
$$

Hence these data allow us to reject at the 5\% significance level test, the null hypothesis $\mathrm{H}_{0}$ that population mean $\mathrm{CO}_{2}$ emission level are the same for all seven countries. This difference can be also seen by the study of Germanwatch. In Figure 1, we see Climate Change Performance Index 2018, a study made by Germanwatch (Burck et al., 2018). 14 indicators within the four categories which are GHG Emissions, Renewable Energy, Energy Use and Climate Policy are taken in consideration to establish this index. If we look at Table 3, index categories are calculated by weighted average. $40 \%$ weighting is given to GHG Emissions, $20 \%$ to Renewable energy, $20 \%$ to Energy use and $20 \%$ to climate policy of the country. The overall calculation gives the ranking scores. As it can be seen from 
the table, despite decreasing growth rates in $\mathrm{CO}_{2}$ emissions, still no country performed well enough to reach the rating "very good" in this year's index.

Figure 1. Climate Change Performance Index 2018

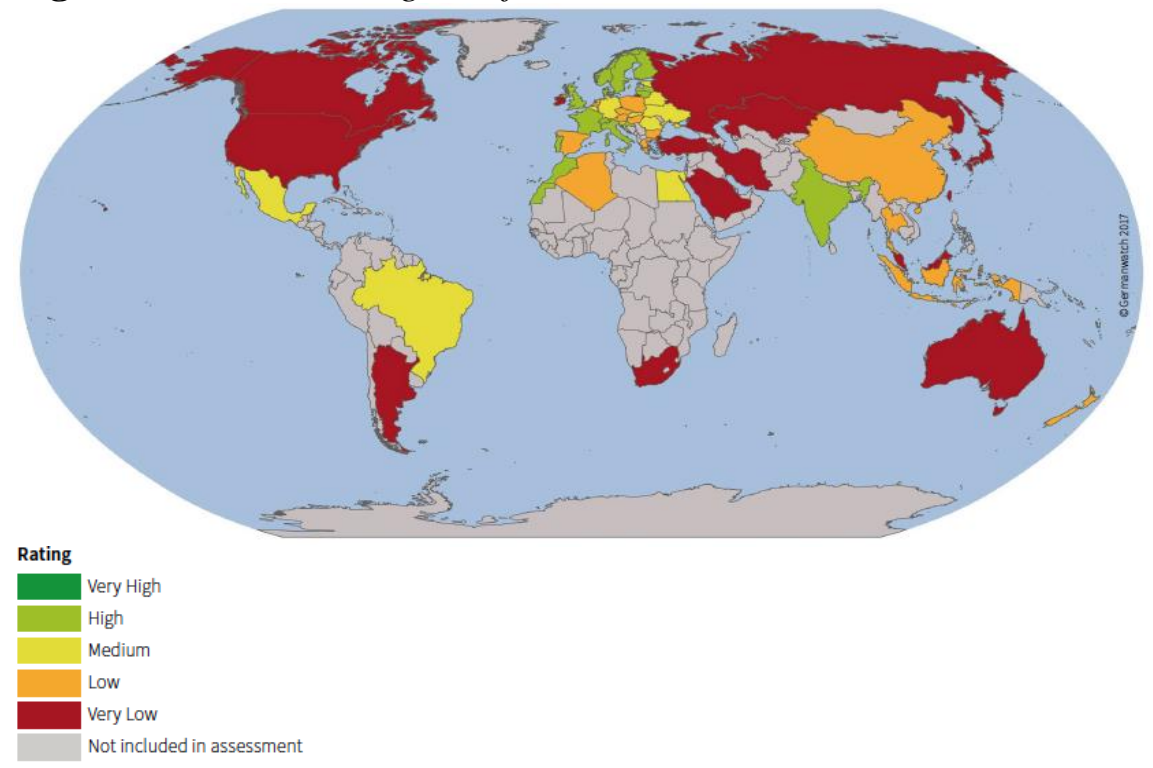

Source: Germanwatch, 2018.

We can see the score and rating found for G7 countries which were our previous statistical analysis data. In dicrease rank we see on 8th position UK which has 66.79 points, on 15th rank France with 59.80 points, on 16th rank Italy with 59.65 points, on 22th rank Germany with 56.58 points and after this one we see a sudden dicrease with Japon, Canada and United States taking place on very low area shown by red. Japon is situated on 50th rank with 35.76 point, Canada on 51th rank with 33.98 point and United States nearly on last rank 56th rank with 25.86 points. Still no country performed well enough to reach the rating "very good" in this year's index. Sweden is leading the list with 74.32 , followed by Lithuania with 69.20 and Morocco with 68.22 point (Germanwatch, 2018).

In climate change reasearch, there exist methods to make prediction for the future and to show the trend of global warming as long as the current activities continue. In the next part, we will give one of them as a projection on climate change. 


\section{Projections on Climate Change}

On November 1988, with the initiative of G7 countries, The Intergovernmental Panel on Climate Change (IPCC) was set up in 1988 by the World Meteorological Organization (WMO) and United Nations Environment Programme (UNEP) to provide policymakers with regular assessments of the scientific basis of climate change, its impacts and future risks, and options for adaptation and mitigation (IPCC, 2018).

Figure 2. Radioactive Concentration Pathways (RCP)

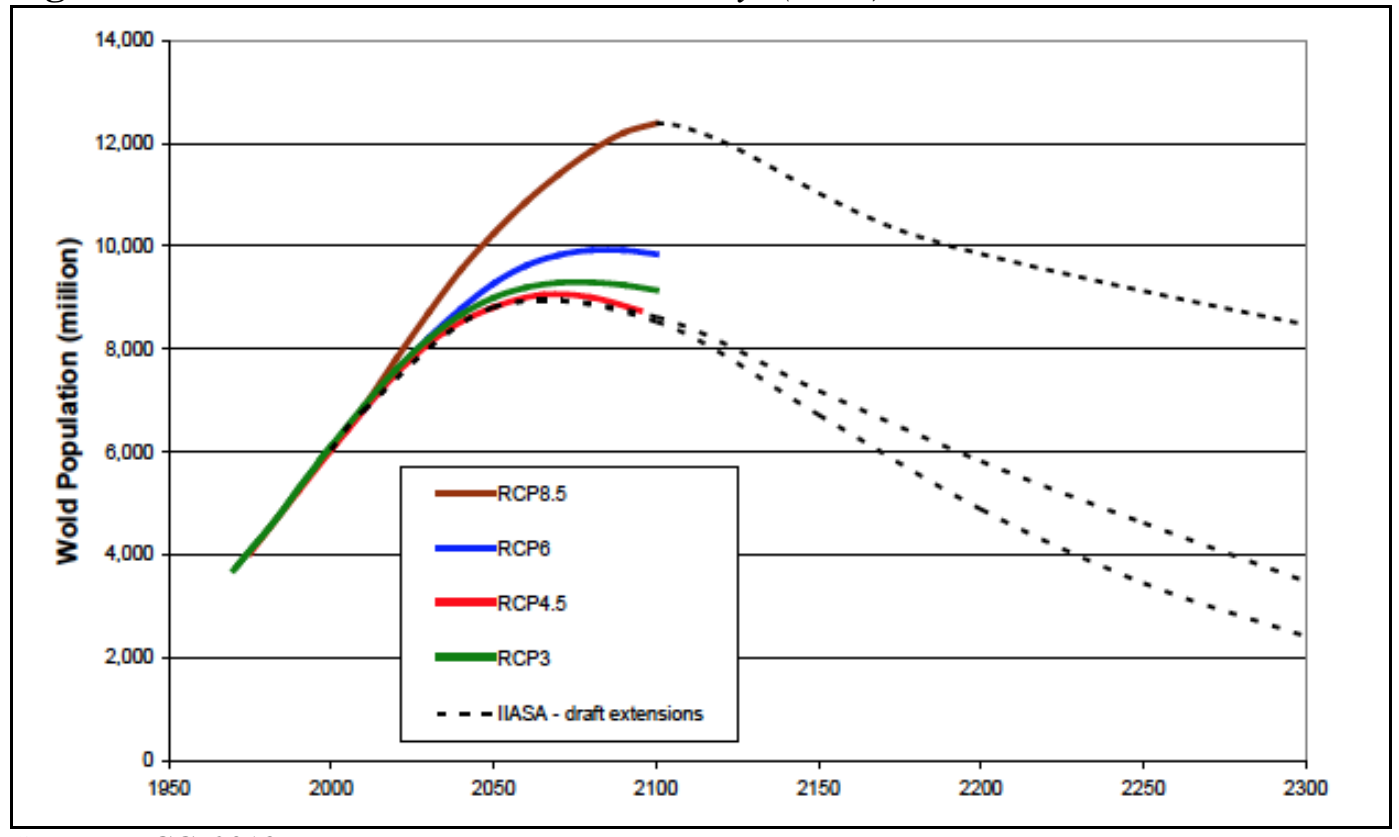

Source: IPCC, 2018.

From 300 scenarios published in the literature, IPCC scientists have defined four evolution profiles of greenhouse gases, ozone and aerosol precursors It exists 4 scenarios because of lack of not founding a mediane solution (Bréon and Luneau, 2015). Those scenarios start from $21^{\text {st }}$ century and continue till 2300 . This is shown in Figure 2. Each scenario named Radioactive Concentration Pathways (RCP) to evolutionary trajectories of greenhouse gas (GHG) concentrations in the atmosphere and land use (Van Vuuren et al., 2011). 
Table 3. Ranking Scores of Countries

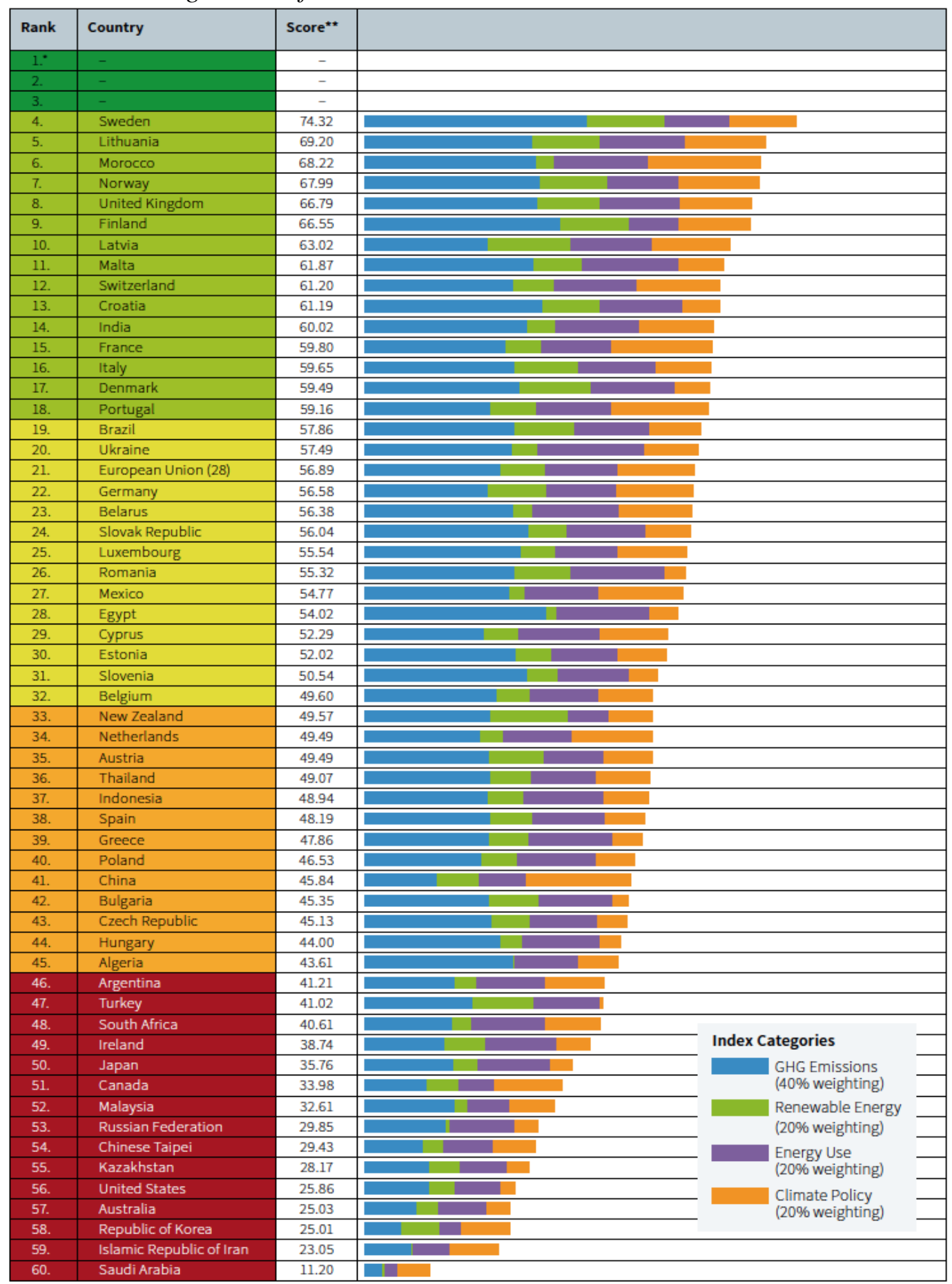

Source: Germanwatch, 2018.

RCP 2,6 is the first option for future predictions developed by the IMAGE modeling team of the Netherlands Environmental Assessment Agency (Van Vuuren et al., 2007). The emission pathway is illustrative for scenarios in the literature leading to very low greenhouse gas concentration levels. Its radiative 
forcing level first reaches a value around $3.1 \mathrm{~W} / \mathrm{m} 2$ mid-century, returning to 2.6 $\mathrm{W} / \mathrm{m} 2$ by 2100 . The aim is to limit global warming at $2 \mathrm{C}$.

RCP 4,5 is a scenario of long-term, global emissions of greenhouse gases which stabilizes radiative forcing at $4.5 \mathrm{~W} / \mathrm{m} 2$ in the year 2100 while never surpassing that esteem (Clarke et al., 2007).

RCP 6 It is a stabilization scenario where total radiative forcing is balanced out after 2100 without overshoot by by work of a scope of innovations and procedures for diminishing greenhouse gas emissions (Fujino et al., 2006).

RCP 8,5 is described by increasing greenhouse gas emissions over time representative for scenarios in the literature leading to high greenhouse gas concentration levels (Riahi et al., 2007).

\section{Conclusions}

In our study, we used international legal cases to analyze climate change and its effects. On the other hand, we made a analysis of variance as statistical method and obtained some informative results about G7, the most industralized countries, and found that there is a difference of $\mathrm{CO}_{2}$ emissions measures even after Kyoto protocol which was one of the most important international agreements. Analysis of variance showed us if there is a difference of means but did not pinpoint the pairs of means that are different. In this aim, our further research will focus on post-hoc tests identifying sample means of $\mathrm{CO}_{2}$ levels that are different from each other. İt has to be noted that burning of fossil fuels releases all manner of pollutants into the air with dangerous effects on human health and into greenhouse gases, which threaten the environment. The main negative impacts of combustion of fossil fuel are air pollution and climate change, along with the major harm coming from the extraction and transport of this kind of energy source. Sustainable energy politics plays a great role in the development of environment-protecting countries (Kartal and Oncel, 2015).

Environment policy and strategy enables the EU economy to be environmentally friendly, protects Europe's natural resources, safeguards the health and subsequently helps the prosperity of individuals living in the European Union. The ecological approaches and enactment secure common natural surroundings, keep air and water clean, guarantee appropriate waste transfer, enhance learning about dangerous chemicals and enable organizations to push toward a practical economy. It is focused on guaranteeing the effective usage of the Paris Agreement and executing the European Union's Emissions Trading System (EU ETS). European Court of Human Rights (ECHR) also protects the rights violated from the states which do not respect the environment and cause harmful Climate Change consequences by their activities. From International view, Climate Change influences legally a variety of ensured human rights. States have an agreed commitment to take serious measures to work on the climate change problems. The events due to climate change, such as floods, rising sea levels, high temperatures, droughts, storms, food shortages, spread of diseases, loss of housing and shelter, cultural extinction, and reduced biodiversity, are 
increasing time by time and these facts create high costs for the economies and the people (Jaimes, 2015b). Climate justice requires that climate action is coherent with existing human rights agreements, obligations, standards and principles. Legal Justice has to be effective in protecting the Environment. The Judiciary has to be independent when exercising its duties. Judicial independence is the basis for the judicial review of the constitutions and the laws. The judges on national and international field have to be very qualified and experienced on environmental issues in order to be able to deliver quality decisions and subsequently protect the planet and the people from the harmful consequences coming from the Environmental and Change Climate violations (Sands, 2016). ${ }^{21}$

\section{Acknowledgments}

This work has been financially supported by Galatasaray University research fund grant no. 16.102.003. The authors wish to acknowledge the support by Galatasaray University Research Foundation.

\section{References}

Almpouras, G., 2018. Penal Environmental Law - The legal Good [in Greek], p. 6-11. Athens.

Bettelheim, E. C. and d'Origny, G. 2002. Carbon sinks and emissions trading under the Kyoto Protocol: a legal analysis.

Boden, T. A., Maryland, G., Andres, R. J. 2010. Global, Regional and National FossilFuel $\mathrm{CO}_{2}$ emissions. Carbon Dioxyde Information Analysis Center, Oak Ridge National Laboratory. U.S. Department of Energy, TN.

Bréon, F. M. and Luneau G. 2015. Atlas du climat: Face aux défis du réchauffement [Climate Atlas: Facing the challenges of global warming]. Edition Autrement, Paris.

Burck, J. et al., 2018. http:// www.germanwatch.org/en/14639.

Clarke, L., Edmonds, J., Jacoby, H., Pitcher, H., Reilly, J. and Richels, R. 2007. Scenarios of Greenhouse Gas Emissions and Atmospheric Concentrations. Sub-report 2.1A of Synthesis and Assessment Product 2.1 by the U.S. Climate Change Science Program and the Subcommittee on Global Change Research. Department of Energy, Office of Biological \& Environmental Research, Washington, 7 DC., USA, p. 154.

Clemens K. 2016. Human Rights and Climate Change. https://medium.com/climatechange-law/6-human-rights-and-climate-change-9ca4b39a9652.

Curson P. 2018. Climate Change and Population Health, Geodate, vol. 31, issue 2, p. 9-13. EPA, 2018. United States Environmental Protection. https://bit.ly/2eekaFO.

European Commission, 2018. https://ec.europa.eu/clima/policies/f-gas_en.

Footprintnetwork, 2018. http://data.footprintnetwork.org/\#/.

\footnotetext{
${ }^{21}$ “The ICJ - along with other international courts and tribunals - can and do play a useful role in developing the law, and contributing to a change of consciousness, and these developments can in turn catalyze new and needed actions: by states, by international organisations, by the private sector, by NGOs, and by individuals".
} 
Fujino, J., Nair, R., Kainuma, M., Masui, T., Matsuoka, Y. 2006. Multi-gas mitigation analysis on stabilization scenarios using AIM global model. Multigas Mitigation and Climate Policy. The Energy Journal Special Issue.

Hoekstra, A. Y. 2013. The Water Footprint of Modern consumer society, Routledge, London, UK.

Hoekstra, A. Y. And Wiedmann, T. O. 2014. Humanity's unsustainable environmental footprint, sciencemag.org, special section: rethinking the global supply chain, vol. 344 , issue 6188.

IPCC, 2018. Intergovernmental Panel on Climate Change, http://ipcc.ch.

Jackson, T. 2009. Prosperity without Growth-Economics for a finite Planet. Esrthscan, London, UK.

Jaimes, V. R. 2015a. The Arctic Athabaskan Petition. Where Accelerated Arctic Warming meets Human Rights, California Western International Law Journal, vol. 45.

Jaimes, V. R. 2015b. Climate Change and Human Rights Litigation in Europe and the Americas, Seatle Journal of Environmental Law, vol. 5.

Kartal, O. and Oncel, A. G. 2015. Comparison of sustainable information technologies for companies, International Journal of Low-Carbon Technologies, vol. 10, issue 4, p. 374-378.

Malm, A., 2015. The Anthropocene Myth. https://bit.ly/1IJYR4J.

McInerney-Lankford, S. 2009. Climate Change and Human Rights, An Introduction to Legal Issues. 33 Harvard Environmental Law Review 431.

Moore, J. W. 2016. Anthropocene or Capitalocene?: Nature, History, and the Crisis of Capitalism (Kairos), ISBN-10: 1629631485, PM Press.

Newbold, P., Carlson, W. L., Thorne, B. 2007. Statistics for Business and Economics, Sixth Edition, Pearson Prentice Hall, ISBN 0-13-188090-X.

Öncel, A. G., 2012. Electricity Consumption and Possible Savings. International Journal of Environmental Pollution and Remediation, vol. 1, issue 1.

Postner, E. A. and Weisbach, D. 2010. Climate Change Justice. Princeton University Press. ISBN: 9780691137759.

Riahi, K. Gruebler, A. and Nakicenovic, N. 2007. Scenarios of long-term socio-economic and environmental development under climate stabilization. Technological Forecasting and Social Change 74, 7, 887-935.

Salman, M. A. 2004. Siobhan McInerney-Lankford, The human Right to water, World Bank.

Sands, P. 2016. Climate Change and the Rule of Law: Adjudicating the Future in International Law, Journal of Environmental Law, 28, 19-35.

Schmidt, G. A. and Arndt, D. 2018. NOAA/NASA-Annual Global Analysis for 2017.

UNEP, "The emissions gap report 2012". United Nations Environment Programme, Nairobi, Kenya.

UNFCC, 2018. United Nations Climate Change. http://unfcc.int.

Van Vuuren et al., 2011. The representative concentration pathways: an overview. Climatic Change 109:5-31 DOI 10.1007/s10584-011-0148-z.

Van Vuuren, D., den Elzen, M., Lucas, P., Eickhout, B., Strengers, B., van Ruijven, B., Wonink, S. and van Houdt, R. 2007. Stabilizing greenhouse gas concentrations at low levels: an assessment of reduction strategies and costs. Climatic Change, http://doi:10.1007/s10584-006-9172-9. 